\section{Prevalência de deficiência de vitamina A e fatores associados em pré-escolares de Teresina, Piauí, Brasil}

\author{
Prevalence and factors associated with \\ vitamin A deficiency in preschool children \\ from Teresina, Piauí, Brazil
}

\author{
Adriana de Azevedo Paiva 1 \\ Patrícia Helen de Carvalho Rondó 2 \\ Cecília Maria Resende Gonçalves-Carvalho ${ }^{3}$ \\ Vanessa Kristinne Illison 2 \\ Joilane Alves Pereira 2 \\ Lourdes Rehder Andrade Vaz-de-Lima 4 \\ Carmem Aparecida de Oliveira ${ }^{4}$ \\ Mirthes Ueda 4 \\ Denise Pimentel Bergamaschi 2
}

\title{
Introdução
}

1 Núcleo de Estudose Pesquisas Epidemiológicas, Universidade Estadual da Paraíba, Campina Grande, Brasil.

2 Faculdade de Saúde Pública, Universidade de São Paulo, São Paulo, Brasil. 3 Departamento de Nutrição, Universidade Federal do Piauí, Teresina, Brasil. 4 Seção de Sorologia e Imunologia, Instituto Adolfo Lutz, São Paulo, Brasil.

Correspondência A. A. Paiva Núcleo de Estudos e Pesquisas Epidemiológicas, Universidade Estadual da Paraíba.

Av. das Baraúnas 351, Campus I, Prédio dos Mestrados, 20 andar. Campina Grande, $P B$ 58100-001, Brasil. aapaiva@yahoo.com.br

\begin{abstract}
Vitamin A deficiency is a public health problem in the Northeast of Brazil. This study aimed to determine the prevalence of vitamin A deficiency and associated factors among preschool children in Teresina, Piauí, Brazil. We studied the serum retinol levels and socioeconomic and demographic characteristics of 631 children from 36 to 83 months of age. The statistical association between each of the above characteristics and serum retinol levels was investigated by univariate and multivariate linear regression analysis. Mean serum retinol was $1.21 \mathrm{mmol} / \mathrm{L}$ (95\%CI: 1.17-1.25 $\mathrm{mol} / \mathrm{L}$ ) and was independent of gender $(p=0.259)$. Prevalence of vitamin $A$ deficiency (retinol $\leq 0.69 \mu \mathrm{mol} / \mathrm{L}$ ) was $15.4 \%$ (95\%CI: 12.7-18.4), with a tendency to decrease with age. Acceptable but not adequate retinol levels (0.70 to $1.04 \mu \mathrm{mol} / \mathrm{L})$ were observed in $29 \%$ of children (95\%CI: 25.2-32.4). There were positive associations between retinol levels and age, income, vitamin A supplementation, and maternal schooling. Vitamin A deficiency appeared as a moderately serious public health problem, emphasizing the importance of strategies to combat this problem in the region.
\end{abstract}

Vitamin A; Vitamin A Deficiency; Preschool Child
A deficiência de vitamina A se destaca entre os principais problemas nutricionais em grande parte da população de países subdesenvolvidos. Crianças de cinco meses a seis anos de idade constituem um grupo de risco, principalmente na presença de morbidades e outras deficiências nutricionais 1 .

Segundo a Iniciativa Micronutriente (Micronutriente Initiative - MI) e o Fundo das Nações Unidas para a Infância (UNICEF) 2, a deficiência de vitamina A compromete o sistema imune de aproximadamente $40 \%$ das crianças com idade inferior a cinco anos em países em desenvolvimento, contribuindo com a morte de cerca de um milhão de crianças a cada ano. De fato, estudos têm demonstrado uma estreita relação entre vitamina A e infecções 3, e até mesmo processos infecciosos leves a moderados podem afetar momentaneamente os valores sangüíneos de retinol.

O Brasil é apontado como uma região de risco de deficiência de vitamina A subclínica 4 . Essa afirmação é sustentada por resultados de estudos realizados a partir da década de 70 , que avaliam a situação da hipovitaminose A nas regiões Sudeste (São Paulo, Rio de Janeiro e Minas Gerais) 5,6,7,8,9,10, Norte (Amazônia Ocidental) 11 e Nordeste (Pernambuco, Paraíba, Bahia, Ceará e Sergipe) 12,13,14,15,16,17,18 do Brasil. 
O Nordeste brasileiro, por se tratar de uma das regiões mais pobres do país, com Índice de Pobreza Humana (IPH) de $46 \%$ 19, onde carências nutricionais como a desnutrição energético-protéica e a anemia ferropriva atingem uma grande parcela da população, tem sido alvo de muitos estudos sobre a situação da hipovitaminose A 12,13,14,15,16,17,18. Entretanto, no Estado do Piauí, não foram realizados até o momento estudos com estimativas da prevalência de hipovitaminose A utilizando-se marcadores bioquímicos.

Em estudo realizado em Teresina, Piauí, Cruz et al. 20 , avaliando a dieta oferecida a crianças assistidas por creches em período integral e parcial, observaram que em ambos os tipos de creches havia uma oferta insatisfatória de vitamina A. Segundo os autores, crianças de dois a quatro anos que permaneciam meio período nas creches recebiam uma dieta com $29 \%$ da adequação da oferta de vitamina A em relação às suas necessidades diárias, quando esperava-se que recebessem pelo menos $50 \%$ das recomendações.

O presente estudo propõe-se a determinar a prevalência de deficiência de vitamina A e identificar os fatores a ela associados, em préescolares com idade entre 36 e 83 meses, matriculados em creches comunitárias do Município de Teresina.

\section{Material e métodos}

Esta investigação é parte de um estudo de coorte realizado na cidade de Teresina, região Nordeste do Brasil, com o objetivo de avaliar o impacto da suplementação com vitamina A no sistema imunológico de pré-escolares 21 .

O estudo envolveu todas as crianças elegíveis com idade entre 36 e 83 meses, freqüentadoras de cinco creches comunitárias localizadas em quatro regiões da cidade (norte, sul, leste e sudeste), escolhidas em um total de 63 creches. As creches foram selecionadas por conveniência por serem recentemente inauguradas e, desta forma, não terem participado de campanhas de suplementação de vitamina A previamente à pesquisa. Em Teresina a suplementação de vitamina A é realizada como uma prática de rotina nos serviços de saúde e, ocasionalmente, a Fundação Municipal de Saúde promove campanhas de distribuição de cápsulas de vitamina A em creches do município.

Os critérios de exclusão da criança no estudo foram: transfusão de sangue e hemoderivados, suplementação com ferro e/ou vitamina A nos últimos seis meses, terapêutica imunossu- pressora ou corticoterápica, doença crônica, infecção por HIV ou processo infeccioso grave no início ou no decorrer da pesquisa.

A inclusão da criança no estudo dependeu da participação da mãe ou responsável em reunião, onde foram expostos os objetivos e procedimentos da pesquisa e aplicado o Termo de Consentimento Livre e Esclarecido. Nessa reunião foi aplicado também um questionário para caracterização sócio-econômica e demográfica das crianças e suas respectivas famílias. A amostra final foi constituída por 631 crianças.

Amostras de sangue ( $2 \mathrm{~mL}$ ) foram colhidas no início da manhã, com a criança em jejum, e obtidas por punção venosa periférica, utilizando-se agulha e seringa descartáveis. As amostras foram armazenadas em tubos secos, transparentes, envolvidos em papel alumínio, para amenizar perdas em decorrência da exposição à luz. Após retração do coágulo e separação por centrifugação (1.500rpm por 10 minutos), as amostras de soro foram acondicionadas em gelo seco e enviadas por via aérea para o Laboratório de Micronutrientes, Faculdade de Saúde Pública, Universidade de São Paulo, para determinação dos níveis de retinol sérico.

As dosagens de retinol foram realizadas pelo método de cromatografia líquida de alta eficiência (HPLC), em equipamento SHIMADZU, conforme metodologia descrita por Erhardt et al. 22

$O$ controle de qualidade da determinação de retinol por HPLC foi realizado pela avaliação da repetibilidade de amostras em duplicata, para uma subamostra de crianças $(\mathrm{n}=163)$. Os resultados revelaram alta confiabilidade dos dados, com coeficiente de correlação intraclasse $\left(r_{i c c}\right)$ igual a 0,894 (IC95\%: 0,863-0,925). A variabilidade dos dados se apresentou de modo independente da magnitude dos mesmos, com 95\% das diferenças entre a primeira e segunda medidas ocorrendo dentro dos limites de concordância, segundo estratégia de análise proposta por Bland \& Altman 23 (Figura 1). Neste gráfico apresenta-se a dispersão de pares de valores dados pelas médias das medidas e pelas diferenças entre elas, sendo apresentados os limites inferior (diferença média -2 desvios padrão) e superior de concordância (diferença média +2 desvios padrão).

Para a interpretação dos níveis de retinol, adotaram-se os pontos de corte recomendados pela Organização Mundial da Saúde (OMS) 24 : (1) deficiente: < 0,35 $\mu \mathrm{mol} / \mathrm{L}$; (2) baixo: 0,35 a

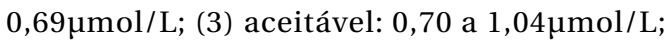
(4) normal: $\geq 1,05 \mu \mathrm{mol} / \mathrm{L}$. A OMS recomenda que regiões onde a prevalência de hipovitaminose A (níveis deficientes e baixos de retinol) atinja de 2 a $10 \%$, de 11 a $19 \%$ ou acima de $20 \%$ 
da população, devam ser consideradas como tendo, respectivamente, problemas leve, moderado e grave de saúde pública.

Após a coleta de dados foi agendada a data na qual foram suplementadas com vitamina $A$ todas as crianças das creches do estudo, exceto aquelas que haviam recebido suplementação da vitamina nos últimos seis meses.

Para o armazenamento e análise estatística dos dados foram utilizados os programas Epi Info versão 6.04 (Centers for Disease Control and Prevention, Atlanta, Estados Unidos) e Stata versão 7 (Stata Corporation, College Station, Estados Unidos). Foi estimada a prevalência de hipovitaminose A e demais níveis de retinol considerando-se as razões de prevalência para a investigação de associação segundo sexo. Utilizou-se o modelo de regressão linear uni e multivariada com variável resposta nível de retinol $(\mu \mathrm{mol} / \mathrm{L})$ e variáveis explanatórias idade da criança, nível de escolaridade da mãe, renda per capita e suplementação prévia com vitamina A.

Investigou-se a relação entre a variável resposta e as explanatórias comparando-se os níveis médios de retinol das categorias das variáveis explanatórias utilizando-se o teste t de Student quando existiam duas categorias, e a análise de variância com um fator fixo (ANOVA) e contrastes de Scheffé, quando a variável explicativa apresentava mais de duas categorias. A decisão estatística foi feita com base no valor de $\mathrm{p}$.

$\mathrm{Na}$ análise multivariada utilizou-se o modelo de regressão linear múltipla considerando-se o nível de retinol (variável contínua) como resposta e, como variáveis explanatórias, as identificadas como importantes na análise univariada: idade (contínua), escolaridade da mãe (dummy), renda (contínua) e suplementação prévia com vitamina A (dicotômica). Os modelos multivariados inicial e final foram os mesmos, uma vez que não foi necessário eliminar nenhuma variável. Tomou-se esta decisão com base nos valores de $\mathrm{p}$ dos testes $t$ de Student parciais.
O protocolo de pesquisa foi analisado e aprovado pelos Comitês de Ética em Pesquisa da Faculdade de Saúde Pública, Universidade de São Paulo e da Universidade Federal do Piauí.

\section{Resultados}

Foram avaliadas 631 crianças com idade entre 36 e 83 meses, sendo $54 \%$ do sexo masculino. Estimou-se um nível médio de retinol sérico de 1,21 $\mathrm{mol} / \mathrm{L}$ (IC95\%: 1,17-1,25 $\mu \mathrm{mol} / \mathrm{L}$ ) para préescolares de ambos os sexos.

A Tabela 1 apresenta a classificação das crianças quanto aos níveis de retinol segundo o sexo. Observa-se que 15,4\% (IC95\%: 12,7-18,4) das crianças apresentavam hipovitaminose A (retinol < 0,70 $\mu \mathrm{mol} / \mathrm{L}$ ) e 29\% (IC95\%: 25,2-32,4) apresentavam níveis aceitáveis de retinol (entre 0,70 e $1,04 \mu \mathrm{mol} / \mathrm{L})$.

Figura 1

Diferença e média dos valores de retinol mensurados em duplicada*.

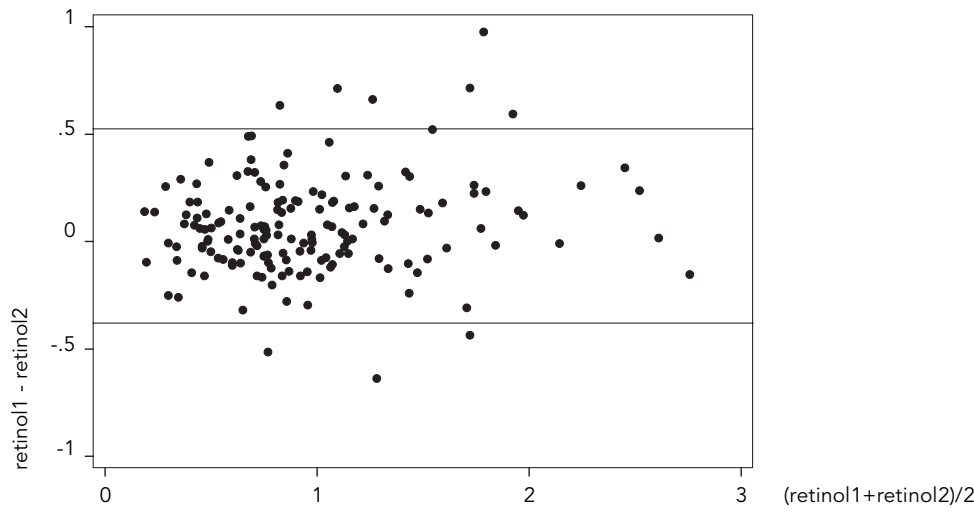

* Valores situados entre os limites de concordância (linhas inferior e superior do gráfico) apresentam boa repetibilidade.

Tabela 1

Distribuição percentual de pré-escolares segundo sexo e níveis séricos de retinol.

\begin{tabular}{lccccc}
\hline Nível de retinol $(\boldsymbol{\mu m o l} / \mathbf{L})$ & $\begin{array}{c}\text { Feminino } \\
(\mathbf{n}=\mathbf{2 8 8})\end{array}$ & $\begin{array}{c}\text { Masculino } \\
(\mathbf{n}=\mathbf{3 4 3})\end{array}$ & $\begin{array}{c}\text { Total } \\
(\mathbf{n}=\mathbf{6 3 1})\end{array}$ & RP & IC95\% \\
\hline Deficiente $(<0,35)$ & 0,69 & 2,04 & 1,43 & 2,94 & $0,62-14,04$ \\
Baixo $(0,35-0,69)$ & 13,89 & 13,99 & 13,95 & 1,01 & $0,68-1,49$ \\
Aceitável $(0,70-1,04)$ & 29,51 & 28,57 & 29,00 & 0,97 & $0,76-1,24$ \\
Normal $(\geq 1,05)$ & 55,90 & 55,39 & 55,63 & 0,99 & $0,86-1,14$ \\
\hline
\end{tabular}


As prevalências de níveis de retinol deficiente, baixo e aceitável variaram segundo a idade da criança, observando-se uma tendência à diminuição da prevalência de níveis baixos $(0,35$ $0,69 \mu \mathrm{mol} / \mathrm{L}$ ) com o aumento da idade. Observouse também tendência de queda da prevalência em crianças com nível deficiente $(<0,35 \mu \mathrm{mol} / \mathrm{L})$ entre 40 e 55 meses de idade (Figura 2).

Observou-se que o nível médio de retinol foi menor entre as crianças mais jovens ( $\mathrm{p}=$ 0,008 ), principalmente quando se comparam crianças na faixa etária de 36 a 47 meses às demais ( $p=0,014)$. Pela análise uni variada observou-se que os níveis médios de retinol não dependeram da cor da criança $(0,714)$ e da escolaridade do pai $(0,515)$ ou da mãe $(0,084)$. A renda per capita variou de $\mathrm{R} \$ 0,00$ a $\mathrm{R} \$ 400,00$ (aproximadamente dois salários mínimos, na época da pesquisa) sendo que as rendas média e mediana foram de aproximadamente $\mathrm{R} \$$ 50,00 . Ressalta-se que $75 \%$ das crianças eram de famílias que tinham renda per capita mensal menor que $\mathrm{R} \$ 66,00$ (pouco mais que / do salário mínimo da época). Observou-se diferença entre os níveis médios de retinol segundo níveis de renda $(\mathrm{p}=0,017)$ (Tabela 2).

Aproximadamente uma entre cada duas crianças estudadas já havia sido suplementada pelo menos uma vez desde seu nascimento (Tabela 2). A informação sobre suplementação prévia com vitamina A era conhecida para $90 \%$ das crianças.

A análise de regressão linear multivariada resultou no modelo contendo as mesmas va-

Figura 2

Distribuição de pré-escolares segundo a prevalência de níveis de retinol sérico deficiente $(<0,35 \mu \mathrm{mol} / \mathrm{L})$, baixo $(0,35-0,69 \mu \mathrm{mol} / \mathrm{L})$ e aceitável $(0,70-1,04 \mu \mathrm{mol} / \mathrm{L})$, e idade (meses).

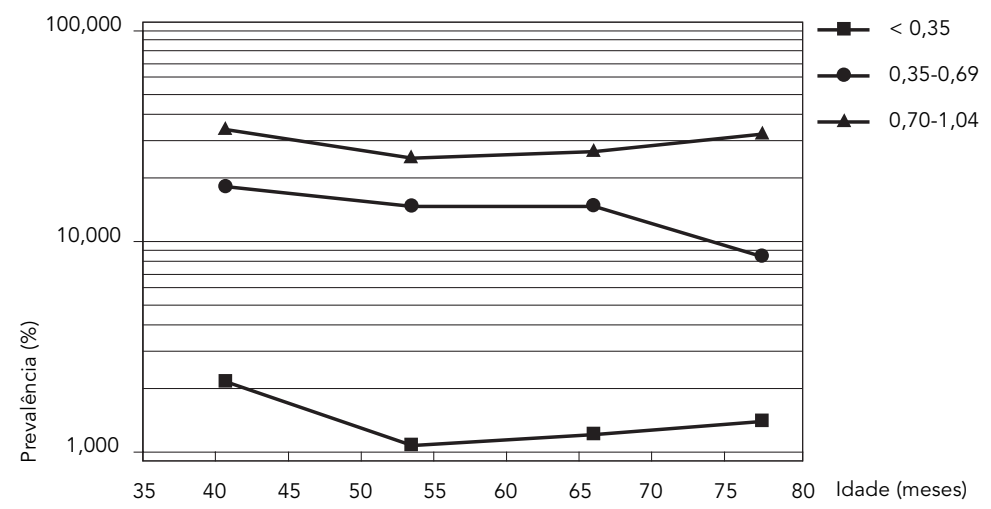

riáveis do modelo inicial: idade, renda per capita, escolaridade da mãe e suplementação prévia, cujos coeficientes brutos (modelo univariado) e ajustados (modelo final) estão apresentados na Tabela 3 .

Com base no modelo de regressão linear múltiplo pode-se dizer que para cada mês a mais de vida seria observado um aumento de $0,005 \mu \mathrm{mol} / \mathrm{L}$ no nível de retinol.

No tocante à escolaridade materna, tomando-se como basal a categoria "analfabeta/alfabetizada”, seria observado um aumento de 0,010 $\mu \mathrm{mol} / \mathrm{L}$ no nível de retinol da criança para a categoria de escolaridade materna "ensino fundamental"; se a mãe apresentasse como escolaridade "ensino médio", ocorreria uma diminuição de $0,221 \mu \mathrm{mol} / \mathrm{L}$ em relação à categoria basal.

Para renda, observar-se-ia uma relação positiva com aumento de $0,293 \mu \mathrm{mol} / \mathrm{L}$ para cada $\mathrm{R} \$ 1,00$, a mais, na renda per capita. Seria observado aumento no nível de retinol em 0,355 $\mu \mathrm{mol} / \mathrm{L}$ para crianças com suplementação prévia com vitamina $\mathrm{A}$.

\section{Discussão}

O presente estudo é pioneiro no Piauí, apresentando resultados importantes uma vez que quantifica o problema da deficiência de vitamina $\mathrm{A}$, que até o momento não havia sido estudado em nenhum município do estado. Os resultados mostram que aproximadamente $57 \%$ das crianças estudadas já haviam recebido suplementação de vitamina A pelo menos uma vez desde o seu nascimento.

Por situar-se em região considerada de risco de hipovitaminose A, o Piauí participa do $\mathrm{Vi}$ tamina A Mais: Programa Nacional de Suplementação de Vitamina A, implementado pelo Ministério da Saúde do Brasil 25. O programa propõe a administração periódica de doses terapêuticas de vitamina A para todas as crianças menores de cinco anos, nas áreas de risco, somada a outros cuidados que integram as ações básicas de saúde.

A prevalência de hipovitaminose A de $15,4 \%$ observada neste estudo indica que este é um problema moderado de saúde pública 24,26 . Cabe ressaltar que a situação torna-se mais preocupante se considerarmos que o estudo envolveu uma amostra de crianças com idade entre 36 e 83 meses, quando o risco da deficiência é menor, o que nos permite especular que o problema poderia ser mais evidente, nessa região, em crianças com menor idade.

Nossos resultados corroboram com outros estudos realizados no Nordeste do Brasil, que 
Caracterização dos pré-escolares segundo variáveis sócio-econômicas e demográficas e nível de retinol ( $\mu$ mol/L).

\begin{tabular}{|c|c|c|c|c|c|}
\hline \multirow[t]{2}{*}{ Características } & \multirow[t]{2}{*}{$\mathrm{n}$} & \multirow[t]{2}{*}{$\%$} & \multicolumn{2}{|c|}{ Nível de retinol $(\mu \mathrm{mol} / \mathrm{L})$} & \multirow[t]{2}{*}{ Valor de $\mathrm{p}^{\star}$} \\
\hline & & & Nível médio & Desvio padrão & \\
\hline \multicolumn{6}{|l|}{ Idade (meses) } \\
\hline $36-47$ & 138 & 21,9 & 1,08 & 0,45 & $0,008^{* *}$ \\
\hline $48-59$ & 184 & 29,2 & 1,27 & 0,59 & $0,014^{\star \star *}$ \\
\hline $60-71$ & 165 & 26,2 & 1,24 & 0,57 & \\
\hline $72-83$ & 143 & 22,7 & 1,22 & 0,48 & \\
\hline \multicolumn{6}{|l|}{ Sexo } \\
\hline Masculino & 343 & 54,4 & 1,19 & 0,52 & 0,259 \\
\hline Feminino & 288 & 45,6 & 1,24 & 0,56 & \\
\hline \multicolumn{6}{|l|}{ Cor } \\
\hline Branca & 135 & 21,7 & 1,23 & 0,54 & $0,714 \#$ \\
\hline Não-branca & 488 & 78,3 & 1,21 & 0,54 & \\
\hline \multicolumn{6}{|l|}{ Escolaridade da mãe } \\
\hline Analfabeta ou alfabetizada & 35 & 5,7 & 1,38 & 0,54 & $0,084^{\star \star}$ \\
\hline Ensino fundamental & 492 & 79,5 & 1,22 & 0,54 & \\
\hline Ensino médio & 92 & 14,9 & 1,14 & 0,49 & \\
\hline \multicolumn{6}{|l|}{ Escolaridade do pai\#\# } \\
\hline Analfabeto ou alfabetizado & 77 & 13,3 & 1,12 & 0,52 & $0,515^{\star \star}$ \\
\hline Ensino fundamental & 436 & 75,6 & 1,23 & 0,54 & \\
\hline Ensino médio & 64 & 11,1 & 1,15 & 1,47 & \\
\hline \multicolumn{6}{|l|}{$\begin{array}{l}\text { Renda per capita } \\
\text { (salários mínimos)\#\#\# }\end{array}$} \\
\hline$<0,25$ & 430 & 70,4 & 1,17 & 0,52 & $0,017^{\star \star}$ \\
\hline $0,25-0,49$ & 150 & 24,5 & 1,30 & 0,56 & \\
\hline $0,50-0,99$ & 29 & 4,8 & 1,19 & 0,47 & \\
\hline $1,00 \mathrm{e}+$ & 2 & 0,3 & 1,97 & 0,69 & \\
\hline \multicolumn{6}{|l|}{ Suplementação anterior } \\
\hline Não & 241 & 42,7 & 1,01 & 0,47 & $<0,001$ \\
\hline $\operatorname{Sim}$ & 324 & 57,3 & 1,33 & 0,55 & \\
\hline
\end{tabular}

* Teste $t$ de Student para amostras independentes;

** ANOVA;

*** Contrastes de Scheffé (idade 36 a 47 vs. 48 a 59);

\# Teste $\mathrm{t}$ de Student;

\#\# Excluindo-se um pai com ensino superior;

\#\# Salário mínimo: R\$240,00.

têm apontado prevalências elevadas de hipovitaminose A em pré-escolares. Em um dos primeiros estudos realizados no Nordeste brasileiro, em 1972, Varela et al. 12 alertaram que a hipovitaminose A constituía um problema de saúde pública potencialmente sério na região da cana-de-açúcar ao sul do Estado de Pernambuco. Segundo os autores, $4 \%$ dos pré-escolares da região tinham níveis de retinol abaixo de $0,35 \mu \mathrm{mol} / \mathrm{L}$, sendo este índice ainda mais elevado entre crianças desnutridas, com $7 \%$ apresentando níveis de retinol sérico abaixo de
$0,35 \mu \mathrm{mol} / \mathrm{L}$ e $18 \%$ abaixo de $0,70 \mu \mathrm{mol} / \mathrm{L}$. Dados mais recentes referentes ao Estado de Pernambuco indicam que essa situação persiste, com prevalência de $19,3 \%$ de crianças menores de cinco anos com níveis séricos de retinol menores que $0,70 \mu \mathrm{mol} / \mathrm{L} 27$.

Na Bahia, Prado et al. 15, investigando a hipovitaminose $\mathrm{A}$ em crianças de 6 a 72 meses de idade na zona rural do Município de Cansanção, e Santos et al. 16, avaliando esta carência em pré-escolares de nove municípios do Estado, observaram, respectivamente, $44,7 \%$ e $54,7 \%$ 
Coeficientes da regressão linear simples e múltipla.

\begin{tabular}{lcccc}
\hline Características & Coeficiente bruto & Valor de $\mathbf{p}$ & Coeficiente ajustado & Valor de $\mathbf{p}$ \\
\hline Idade (meses) & 0,003 & 0,054 & 0,005 & 0,001 \\
Escolaridade da mãe & & & & \\
$\quad$ Analfabeta/Alfabetizada & 1,000 & & 1,000 & \\
$\quad$ Ensino fundamental & 0,005 & 0,926 & 0,010 & 0,018 \\
Ensino médio & $-0,094$ & 0,141 & $-0,221$ & 0,007 \\
Renda (Reais) & 0,001 & 0,040 & 0,293 & 0,001 \\
Suplementação anterior & & & 1,000 & \\
Não & 1,000 & $<0,001$ & 0,355 & $<0,001$ \\
Sim & 0,326 & &
\end{tabular}

de crianças com valores de retinol sérico $<0,70$ $\mu \mathrm{mol} / \mathrm{L}$. Estas cifras refletem a situação no início da implantação do Programa de Combate à Deficiência de Vitamina A, podendo ter havido alteração a partir de então.

Embora já tenha sido sugerido que crianças do sexo masculino sejam mais suscetíveis à deficiência de vitamina A que crianças do sexo feminino 28 , no presente estudo os níveis médios de retinol sérico foram semelhantes em ambos os sexos, como descrito em outros estudos 6,7,29.

Nossos achados que relacionam a prevalência de nível de retinol com a idade da criança são semelhantes aos observados por Santos et al. 16 em estudo envolvendo pré-escolares na Bahia. Segundo nossos resultados, a prevalência de hipovitaminose A parece diminuir com a idade, com tendência de queda entre 40 e 80 meses de idade para crianças com níveis baixos de retinol (0,35-0,69 $\mathrm{mol} / \mathrm{L})$. A curva de prevalência para crianças com nível deficiente deve ser interpretada com cuidado uma vez que este grupo apresentou um pequeno número de crianças $(n=9)$. É possível que a idade seja apenas uma variável de confusão e que essa tendência esteja associada verdadeiramente a fatores tais como crescimento físico, efeito adverso de infecções por vírus e bactérias e das infestações parasitárias comuns nessa faixa etária, ou ainda por uma maior diversificação do padrão dietético observado em crianças mais velhas.

$\mathrm{O}$ estudo dos fatores determinantes da hipovitaminose A em crianças tem sugerido que essa carência estaria mais associada ao baixo consumo de alimentos fontes da vitamina, determinado por questões culturais ou por hábitos alimentares próprios dessa faixa etária, do que propriamente a fatores econômicos 8 . Contudo, variáveis ambientais, sociais e econômi- cas têm-se apresentado relacionadas com os níveis de retinol em alguns estudos 29,30.

No presente estudo, além da idade da criança, que favoreceu um aumento médio de $0,005 \mu \mathrm{mol} / \mathrm{L}$ de retinol para cada mês de vida, a escolaridade da mãe, a renda per capita e a suplementação prévia com vitamina A influenciaram os níveis médios de retinol sérico. $\mathrm{O}$ fato de a mãe ter cursado o ensino fundamental completo ou incompleto contribuiu com um aumento de $0,010 \mu \mathrm{mol} / \mathrm{L}$ no nível médio de retinol da criança, comparadas às mães da categoria basal (analfabeta/alfabetizada). Fernández et al. 30, incluindo a educação materna em um modelo de regressão multivariada, observaram que para cada ano de aumento no nível de educação da mãe, os níveis de retinol aumentavam em média 0,5544 $\mu \mathrm{g} / \mathrm{dL}(0,0194 \mu \mathrm{mol} / \mathrm{L})$.

No presente estudo observou-se uma redução de $0,221 \mu \mathrm{mol} / \mathrm{L}$ nos valores de retinol para as crianças cujas mães haviam cursado o ensino médio. Especulamos que mães com maior escolaridade tenham mais possibilidades de trabalho fora de casa, e assim, os cuidados com a criança poderiam estar reduzidos, predispondo a criança a um maior risco de infecção e piores práticas alimentares, ocasionando a redução dos níveis de retinol sérico. No entanto, é preciso considerar a complexidade das interações entre escolaridade e renda, uma vez que o trabalho das mães poderia influenciar na renda, e desta forma, contribuir para uma melhor alimentação e cuidados gerais com a saúde. Assim, evidências adicionais são necessárias para compreender os presentes achados.

Apesar de neste estudo 95\% das famílias apresentaram renda per capita inferior a $1 / 2$ salário mínimo, indicando homogeneidade no baixo poder aquisitivo da população estudada, a renda per capita mensal (salários mínimos) 
apresentou relação positiva com o nível de retinol sérico, com aumento médio de $0,002 \mu \mathrm{mol} / \mathrm{L}$ para cada $\mathrm{R} \$ 1,00$, a mais, na renda per capita.

A suplementação prévia com doses terapêuticas de vitamina A foi, sem dúvida, o fator que mais influenciou os níveis de retinol das crianças deste estudo. O Programa de Combate à Deficiência de Vitamina $\mathrm{A}$ foi implantado em Teresina na década de 90 , sendo realizado simultaneamente às campanhas de vacinação. Posteriormente passou a ser realizado em postos de saúde independente de campanhas de vacinação, em visitas domiciliares por agentes de saúde, ou ainda com ações em creches do município.

O benefício da suplementação com doses massivas de vitamina $\mathrm{A}$ em áreas de risco de deficiência clínica e subclínica é um consenso, sendo eficaz na recuperação dos níveis de vita- mina A, bem como na diminuição da morbidade e mortalidade infantil 2,31. Nosso estudo revela a importância da suplementação na região estudada, indicando que a administração periódica de vitamina A é uma ferramenta fundamental para prevenção e controle da hipovitaminose A. Evidencia-se, portanto, a importância de programas de suplementação com alta cobertura, sobretudo para as crianças de menor idade.

Ressalta-se, sobretudo, a necessidade urgente de educar a população e incentivar o consumo de alimentos fontes de vitamina A e seus precursores, como medidas auto-sustentáveis a longo prazo e que merecem lugar de destaque nas políticas públicas da região. Ainda, é importante o incentivo à fortificação de alimentos, o combate à desnutrição e o controle de doenças parasitárias.

\section{Resumo}

A deficiência de vitamina A constitui um problema de saúde pública no Nordeste brasileiro. O objetivo deste estudo foi determinar a prevalência da deficiência de vitamina A e os fatores associados em pré-escolares de Teresina, Piauí, Brasil. Os níveis de retinol sérico foram determinados por HPLC, e foram investigadas as características sócio-econômicas e demográficas de 631 crianças com idade de 36 a 83 meses. Investigou-se a associação entre os níveis de retinol e as variáveis de interesse por análise de regressão linear uni e multivariada. O nível médio de retinol foi de $1,21 \mathrm{mmol} / \mathrm{L}$ (IC95\%: 1,17-1,25 $\mu \mathrm{mol} / \mathrm{L})$, independente do sexo ( $p=$ 0,259). A hipovitaminose A (retinol $\leq 0,69 \mu \mathrm{mol} / \mathrm{L}$ ) foi observada em 15,4\% das crianças (IC95\%: 12,7-18,4), com tendência à diminuição com o avanço da idade; 29\% das crianças (IC95\%: 25,2-32,4) tinham valores aceitáveis de retinol, mas não adequados $(0,70$ a 1,04 $\mu \mathrm{mol} / \mathrm{L}$ ). Encontrou-se associação positiva entre níveis de retinol e idade, renda per capita, suplementação prévia com vitamina A e escolaridade materna. A prevalência de hipovitaminose A representa um problema moderado de saúde pública, ressaltando a importância das estratégias de combate a essa carência na região.

Vitamina A; Deficiência de Vitamina A; Pré-escolar

\section{Colaboradores}

A. A. Paiva participou do desenvolvimento do protocolo de estudo, coletou e analisou os dados, interpretou os resultados e escreveu o artigo. P. H. C. Rondó colaborou no desenvolvimento do protocolo de estudo, interpretação dos resultados e redação do artigo. C. M. R. Gonçalves-Carvalho contribuiu no desenvolvimento do protocolo de estudo, interpretou os resultados e revisou o artigo. V. K. Illison realizou as análises de retinol por HPLC e revisou o artigo. J. A. Pereira coletou os dados, interpretou os resultados e revisou o artigo. L. R. A. Vaz-de-Lima e C. A. Oliveira participaram do desenvolvimento do protocolo de estudo, análises de HIV (critério de exclusão do estudo) e revisão do artigo. M. Ueda realizou as análises de HIV (critério de exclusão do estudo) e revisou o artigo. D. P. Bergamaschi contribuiu no desenvolvimento do protocolo de estudo, fez as análises estatísticas, interpretou os resultados e escreveu o artigo. 


\section{Agradecimentos}

Os autores sinceramente agradecem à Secretaria $\mathrm{Mu}$ nicipal da Criança e do Adolescente de Teresina, Piauí, especialmente à Dra. Maria das Neves M. de S. Bezerra, pelo apoio no desenvolvimento da pesquisa, e às nutricionistas Iracelma Lopes e Graciane Oliveira pelo auxílio na etapa de coleta de dados.

\section{Referências}

1. McLaren DS, Frigg M. Sight and life manual on vitamin A deficiency disorders (VADD). 2nd Ed. Basel: Task Force Sight and Life; 2001.

2. Micronitrient Initiative/United Nations Children's Fund. Vitamin and mineral deficiency: a global progress report. http://www.micronutrient.org (acessado em 15/Nov/2005).

3. Paiva AA, Rondó PHC, Oliveira CAF, Vaz-de-Lima LRA, Ueda M, Carvalho CMRG, et al. The impact of vitamin A supplementation on the cellular immune system of preschool children. In: Vorster HH, Blaavw R, Dhansay MA, Kuzwayo PMN, Moeng L, Wentzel-Viljoen E, editors. Proccedings of the 18th International Congress of Nutrition [CDROM]. Palaiseau: Danone Institute; 2005.

4. Ramalho RA, Flores H, Saunders C. Hipovitaminose A no Brasil: um problema de saúde pública. Rev Panam Salud Pública 2002; 12:117-22.

5. Roncada MJ, Wilson D, Okani ET, Aminos S. Prevalência de hipovitaminose A em pré-escolares de município da área metropolitana de São Paulo, Brasil. Rev Saúde Pública 1984; 18:218-24.

6. Gonçalves-Carvalho CMR, Amaya-Farfan J, Wilke BC, Vencovsky R. Prevalência de hipovitaminose A em crianças da periferia do Município de Campinas, São Paulo, Brasil. Cad Saúde Pública 1995; 11:85-96.

7. Ferraz IS, Danelussi JC, Vannucchi H. Vitamin A deficiency in children aged 6 to 24 months in São Paulo State, Brazil. Nutr Res 2000; 20:757-68.

8. Ramalho RA, Anjos LA, Flores H. Valores séricos de vitamina A e teste terapêutico em pré-escolares atendidos em uma unidade de saúde do Rio de Janeiro, Brasil. Rev Nutr 2001; 14:5-12.

9. Araújo RL, Araújo MBDG, Sieiro RO, Machado, RDP, Leite BV. Diagnóstico da situação da hipovitaminose A e da anemia nutricional na população do Vale do Jequitinhonha, Minas Gerais, Brasil. Arch Latinoam Nutr 1986; 4:642-53.

10. Santos MA, Rezende EG, Lamournier JA, Galvão MAM, Bonomo E, Leite RC. Hipovitaminose A em escolares da zona rural de Minas Gerais. Rev Nutr 2005; 18:331-9.

11. Marinho HA. Prevalência da deficiência de vitamina A em pré-escolares de três capitais da Amazônia Ocidental Brasileira [Tese de Doutorado]. São Paulo: Faculdade de Saúde Pública, Universidade de São Paulo; 2000.
12. Varela RM, Teixeira SG, Batista M. Hypovitaminosis A in the sugarcane zone of southern Pernambuco State, Northeast Brazil. Am J Clin Nutr 1972; 25 : 800-4.

13. Santos LMP, Dricot JM, Asciutti L, Dricot-d'Ans C. Xerophthalmia in the state of Paraíba, northeast of Brazil: clinical findings. Am J Clin Nutr 1983; 38:139-44.

14. Flores H, Campos F, Araújo CRC, Underwood BA. Assessment of marginal vitamin A deficiency in Brazilian children using the relative dose response procedure. Am J Clin Nutr 1984; 40:1281-9.

15. Prado MS, Assis AMO, Martins MC, Nazaré MPA, Rezende IFB, Conceição MEP. Hipovitaminose A em crianças de áreas rurais do semi-árido baiano. Rev Saúde Pública 1995; 29:295-300.

16. Santos LMP, Assis AMO, Martins MC, Araújo MPN, Morris SS, Barreto ML. Situação nutricional e alimentar de pré-escolares no semi-árido da Bahia (Brasil): II - hipovitaminose A. Rev Saúde Pública 1996; 30:67-74.

17. Martins MC, Santos LMP, Assis AMO. Prevalece of hypovitaminosis A among preschool children from northeastern Brazil, 1998. Rev Saúde Pública $2004 ; 38: 1-6$.

18. Fernandes TFS, Diniz AS, Cabral PC, Oliveira RS, Lola MMF, Silva SMM, et al. Hipovitaminose A em préescolares de creches públicas do Recife: indicadores bioquímico e dietético. Rev Nutr 2005; 18:471-80.

19. Programa das Nações Unidas para o Desenvolvimento. Relatório do desenvolvimento humano, 1997. Lisboa: Trinova Editora; 1997.

20. Cruz GF, Santos RS, Carvalho CMRG, Moita GC. Avaliação dietética em creches municipais de Teresina, Piauí, Brasil. Rev Nutr 2001; 14:21-32.

21. Paiva AA. Suplementação de vitamina A em préescolares da Cidade de Teresina, Piauí: avaliação de parâmetros bioquímicos, marcadores imunológicos celulares e do estado nutricional [Tese de Doutorado]. São Paulo: Faculdade de Saúde Pública, Universidade de São Paulo; 2005.

22. Erhardt JG, Mack H, Sobeck U, Biesalski HK. $\beta$ carotene and $\alpha$-tocopherol concentration and antioxidant status in buccal mucosal cells and plasma after oral supplementation. Br J Nutr 2002; 87:471-5.

23. Bland JM, Altman DG. Statistical methods for assessing agreement between two methods of clinical measurement. Lancet 1986; 8:307-10. 
24. World Health Organization. Indicators for assessing vitamin A deficiency and their application in monitoring and evaluating intervention programmes. Geneva: World Health Organization; 1996.

25. Secretaria de Atenção à Saúde, Ministério da Saúde do Brasil. Vitamina A mais: Programa Nacional de Suplementação de Vitamina A - condutas gerais. Brasília: Ministério da Saúde; 2004. (Série A. Normas e Manuais Técnicos).

26. World Health Organization. Control of vitamin A deficiency and xerophthalmia, Jakarta, 1980. Geneva: World Health Organization; 1982. (WHO Technical Report Series, 672).

27. Instituto Nacional de Alimentação e Nutrição/Instituto Materno-Infantil de Pernambuco/Departamento de Nutrição, Universidade Federal de Pernambuco/Secretaria Estadual de Saúde de Pernambuco. II Pesquisa Estadual de Saúde e Nutrição: saúde, nutrição, alimentação e condições sócio-econômicas no Estado de Pernambuco, 1997. Recife: Instituto Nacional de Alimentação e Nutrição/Instituto Materno-Infantil de Pernambuco/ Departamento de Nutrição, Universidade Federal de Pernambuco/Secretaria Estadual de Saúde de Pernambuco; 1998.
28. Oomen HAPC, McLaren DS, Escapini H. Epidemiology and public health aspects of hypovitaminosis A. A global survey on xerophthalmia. Trop Geogr Med 1964; 16:271-315.

29. Nestel P, Melara A, Rosado J, Mora JO. Vitamin A deficiency and anemia among children 12-71 months old in Honduras. Rev Panam Salud Pública 1999; 6:34-43.

30. Fernández DC, Calvo TA, Monge-Rojas R. Deficiencia de vitamina A en niños preescolares: un problema reemergente en Costa Rica? Arch Latinoam Nutr 2003; 53:267-70.

31. Beaton GH, Martorell R, Aronson KA, Edmonston B, McCabe G, Ross C, et al. Effectiveness of vitamin A supplementation in the control of young child morbidity and mortality in developing countries. Geneva: United Nations Administrative Committee on Coordination Subcommittee on Nutrition; 1993. (Nutrition Discussion Paper, 13).

Recebido em 24/Ago/2005

Versão final reapresentada em 08/Dez/2005

Aprovado em 02/Fev/2006 